\title{
BANCA MARCH Palma de Mallorca - España
}

FELIPE LAFITA PARDO, Dr. Arquitecto

Este edificio constituye la 1.: fase del complejo total y alberga las oficinas bancarias, con: parte cultural, viviendas de los conserjes y apartamentos para personal de la organización. La 2: fase - que se construirá más tarde- comprenderá: locales comerciales, oficinas, uso hotelero, viviendas y apartamentos.

La manzana se ha ordenado de forma abierta, con manifiesto beneficio para los usuarios y para la ciudad.

El articulo describe la solución urbanistica adoptada, la distribución y justificación de cada planta, así como los accesos y circulaciones, acabados exteriores e interiores del edificio de la 1.: fase, todo él destinado a la Banca March.

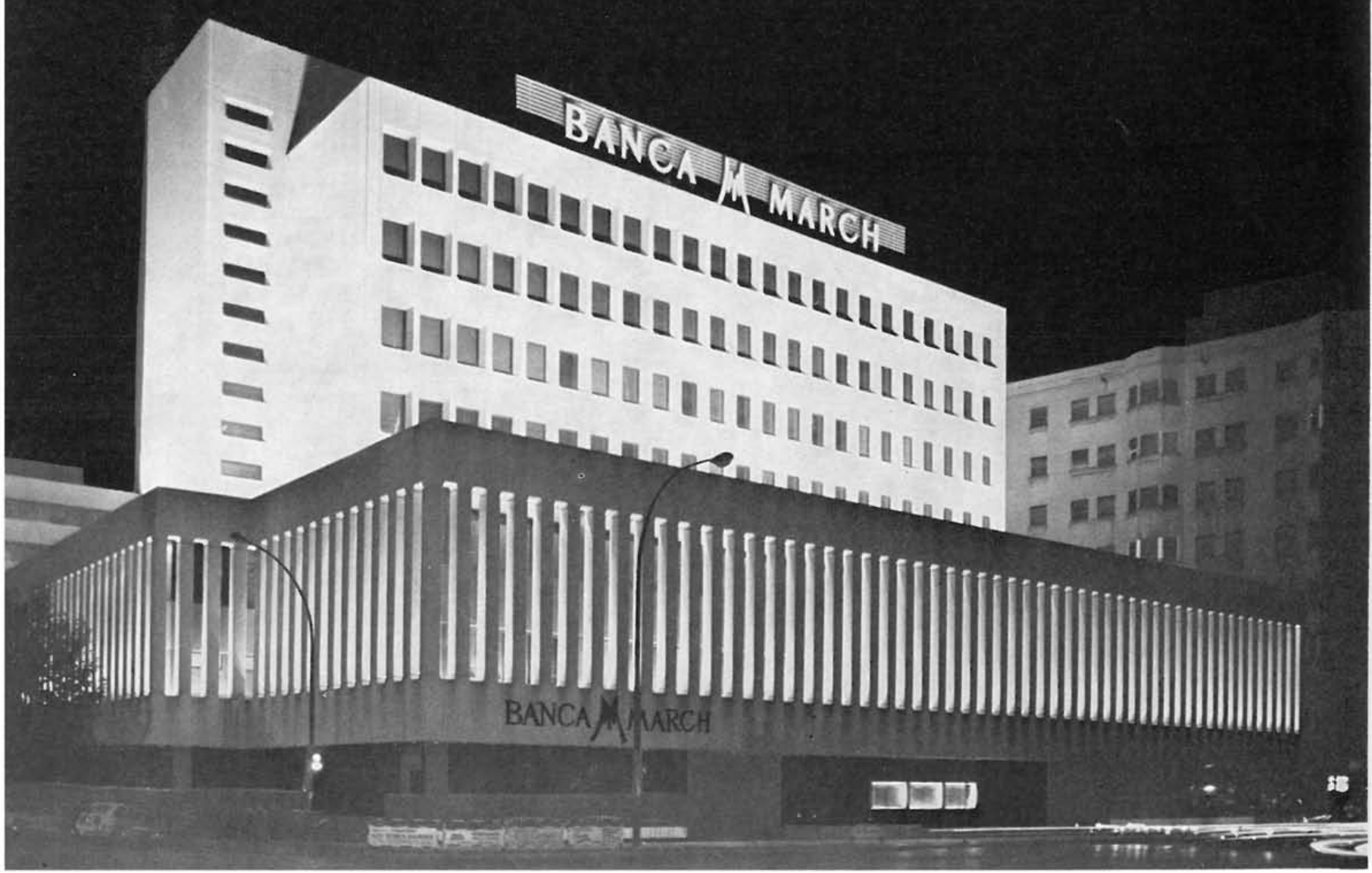




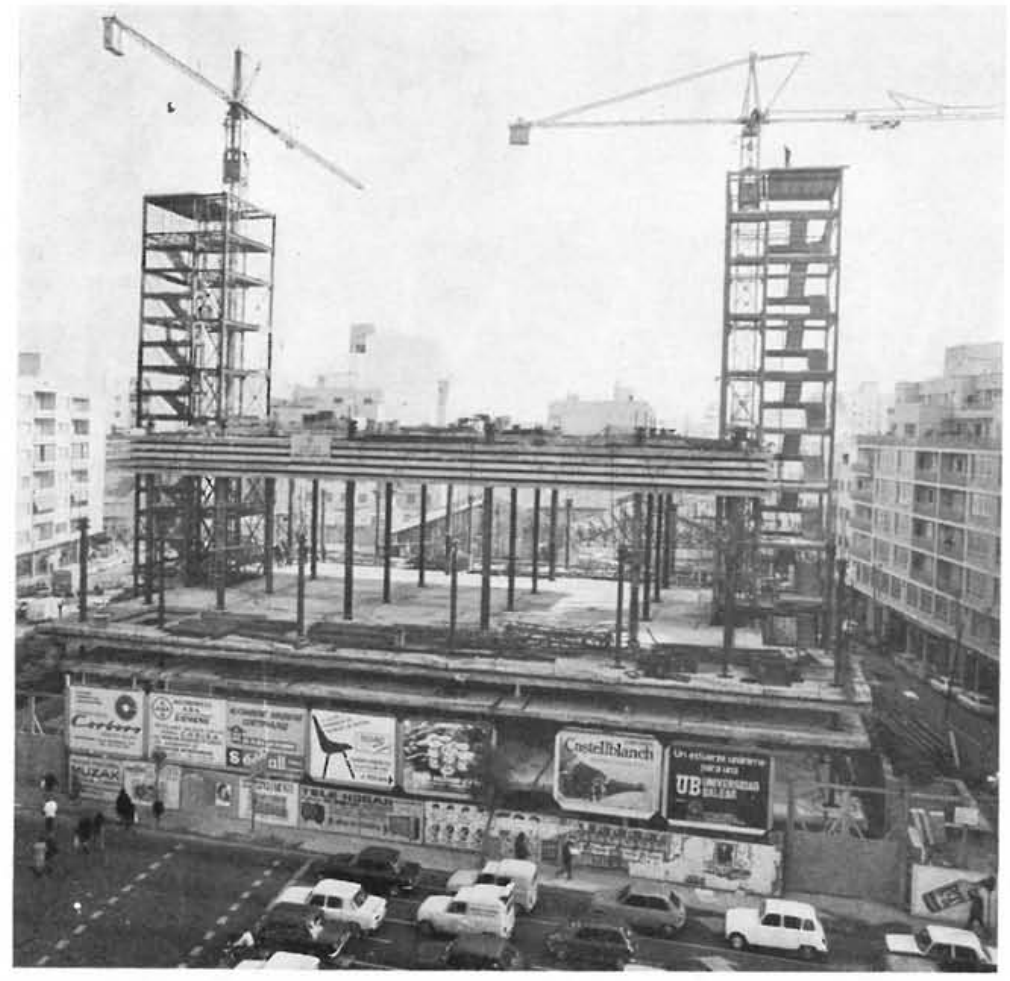

Vista del montaje de estructura compuesta por dos torres metálicas, soportes metálicos y forjados de hormigón realizados en el suelo y subidos por paquetes mediante gatos por el sistema Lift-Slab.

$145-98$

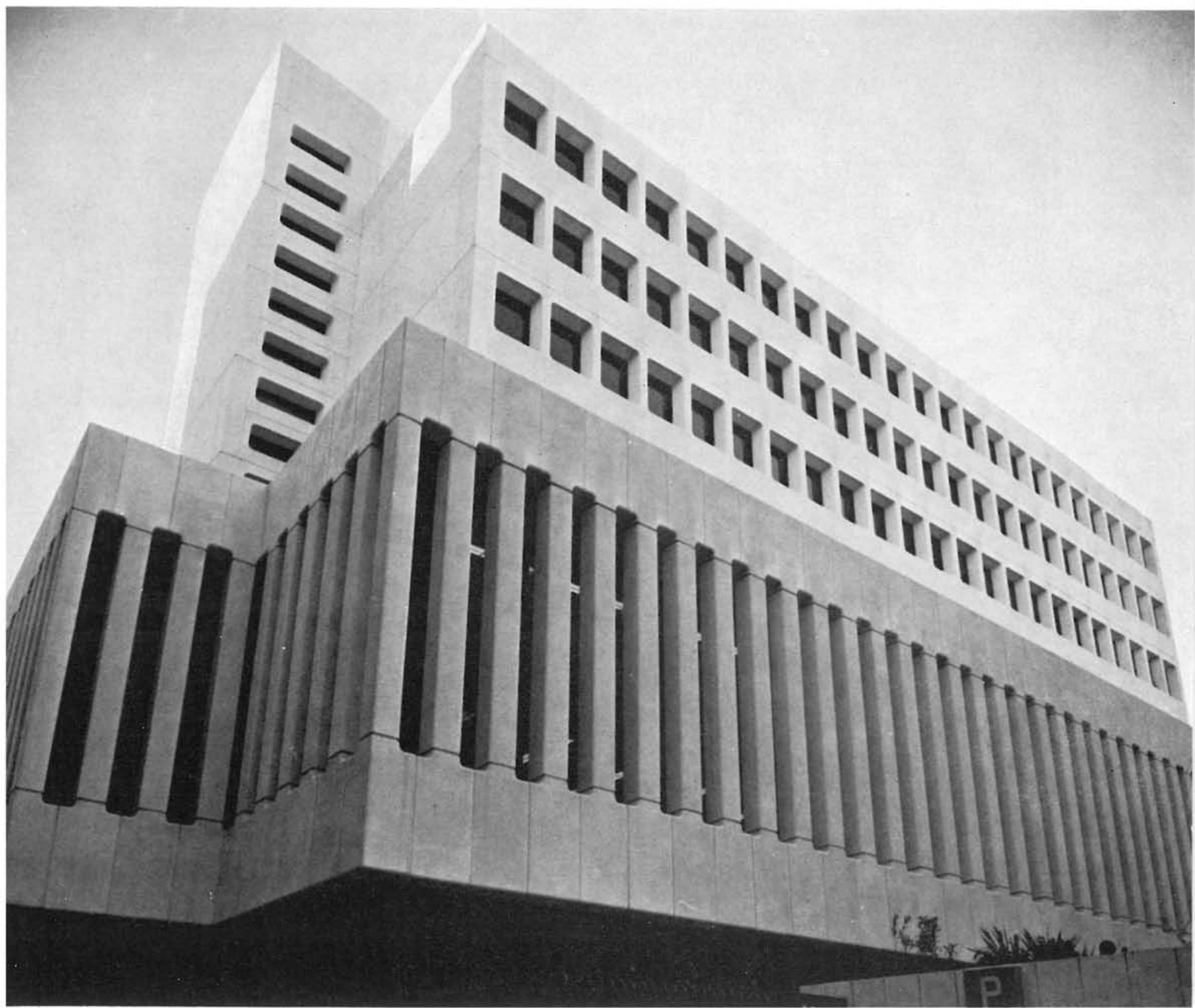


El edificio promovido por la Banca March para su Sede Social en Palma de Mallorca constituye la $1 .^{\text {a }}$ fase de un complejo.

Se ha realizado en un solar $\left(5.280 \mathrm{~m}^{2}\right)$ situado en dicha ciudad, limitado por la Avda. Alejandro Rosselló y las calles Arturo Rizzi, Luis Martí y Mistral.

El complejo se hará en forma de manzana abierta sobre una plataforma, situada a la cota $+2,82$, con accesos desde varios puntos de las calles. Se prevé entre la Banca March y las edificaciones que componen la 2. ${ }^{\text {. }}$ fase y sobre la plataforma un agradable espacio de uso público con jardines, porches y patios abiertos.

El edificio de la Banca March consta de oficinas de uso comercial, aunque también dispone de una parte cultural y viviendas para conserjes, así como apartamentos destinados al personal de la organización.

En cuanto a la 2. ${ }^{\text {a }}$ fase del proyecto — de construcción posterior- tendrá: locales comerciales, oficinas, uso hotelero, viviendas y apartamentos.

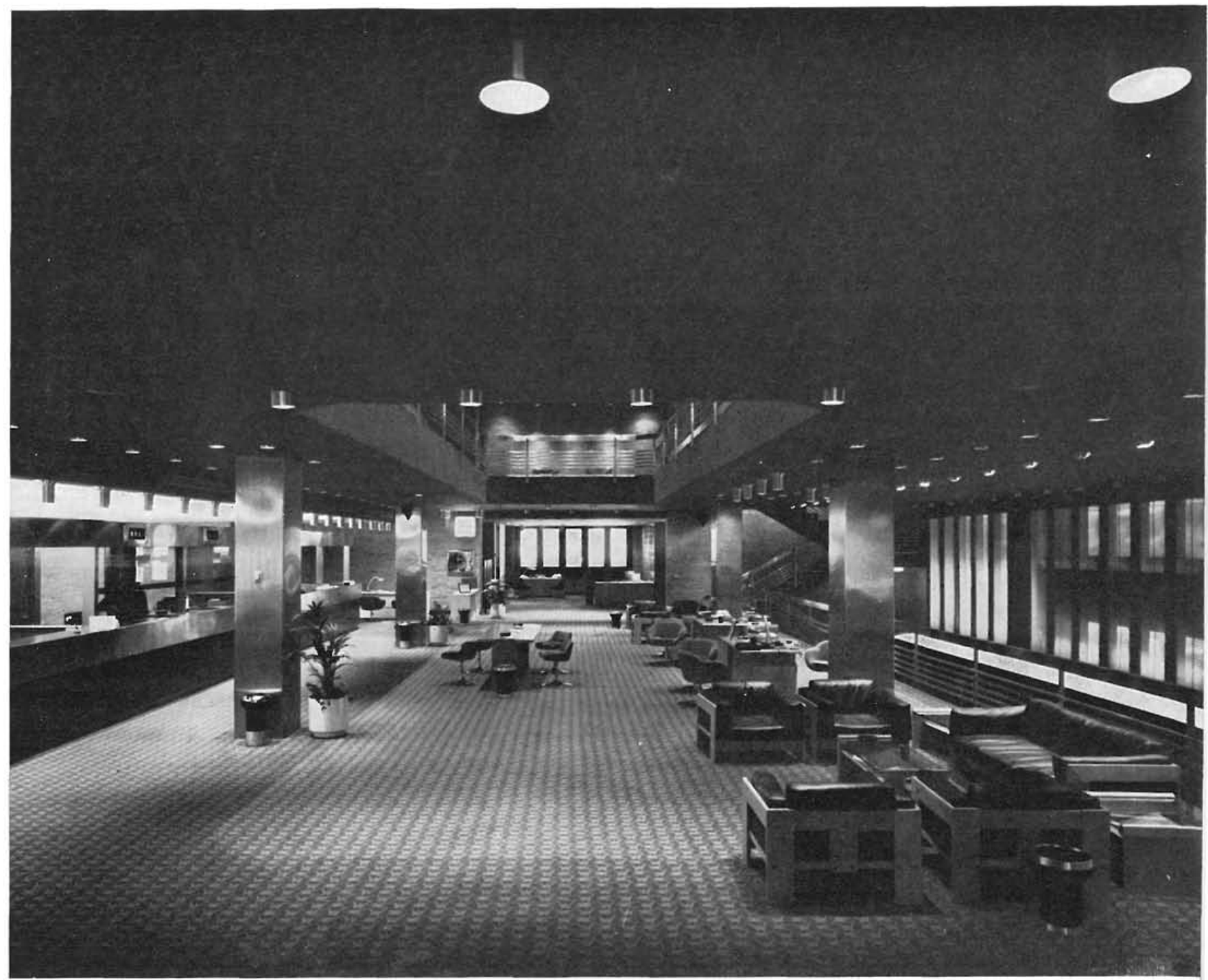


Ciñéndonos de aquí en adelante a la Banca March podemos decir que se divide en cuatro partes:

a) Zona subterránea, ocupada por el primer y segundo sótano, así como por la entreplantasemisótano de libre acceso al público.

b) Planta de acceso.

c) Dos plantas de bandeja.

d) Cuerpo aéreo de cuatro plantas tipo, más un pequeño ático con los núcleos de maquinaria de los ascensores.

La cota de la planta más baja está a $-6,68 \mathrm{~m}$, mientras que la del ático se encuentra a $+31,02 \mathrm{~m}$.

Se ha llegado a esta distribución teniendo en cuenta los aspectos funcional, de comunicaciones verticales, y volumétrico y visual.

Respecto al aspecto funcional, las dos plantas de sótano albergan, aparte de los aparcamientos, ciertos departamentos de la Banca que, por su carácter privado o de gran seguridad, deben ocupar zonas bajas y a ser posible subterráneas; archivos y naves acorazadas.

Por otra parte, el aspecto público de la Banca se materializa en el patio de público y las dos escaleras principales hacia lo alto y lo ancho de las tres siguientes plantas: semisótano, planta de acceso y planta $1 .^{\text {a }}$ de bandeja.

Esta relación a través de las dos escaleras de público no impide que ciertos departamentos, como el de valores, se encuentre a la misma cota del patio de público de la entreplanta, por motivos funcionales, dado que dicho departamento tiene los dos aspectos: relación con el público y privacidad de la cámara fuerte.

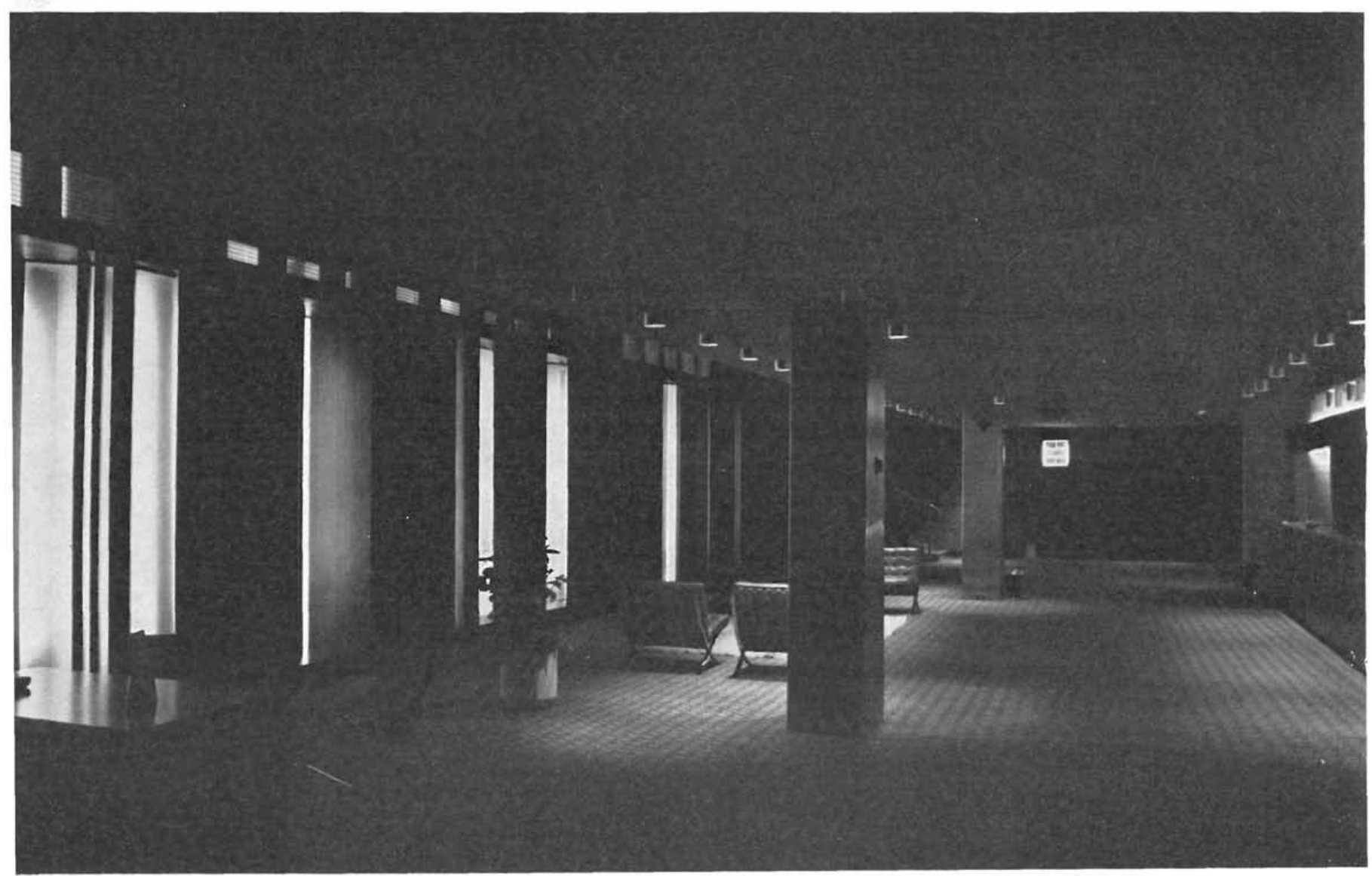




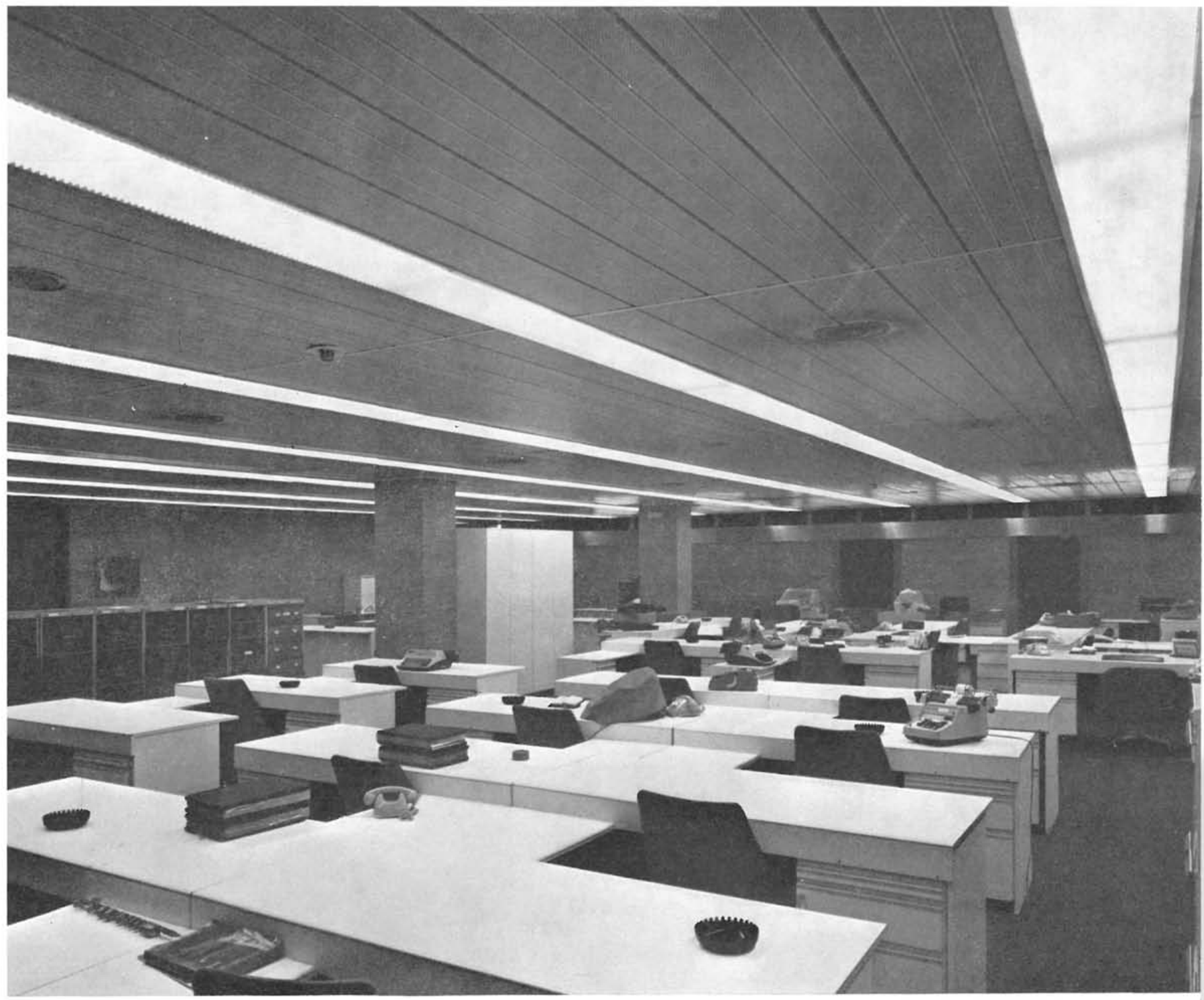

Mediante dos escaleras se obtiene el nexo de unión entre los tres patios de público superpuestos: uno en la planta de acceso y los otros dos, uno encima y otro debajo de ésta.

Respecto a las comunicaciones verticales, el principal elemento de conexión se establece por escaleras y ascensores que recorren en su totalidad la altura, desde el último sótano a la planta del ático.

Los dos núcleos de comunicaciones verticales (constituidos por grupos de tres ascensores y escalera cada uno) son los ejes vertebrales del edificio y se han realizado en las alas del cuerpo central de plantas tipo y perforando el resto de plantas inferiores. En los laterales y en la parte más alta se han resuelto en saliente, como piezas escultórico-volumétricas, en toda su anchura.

Estos núcleos verticales pueden abrir en ciertas plantas y en otras ser cerrados, de forma potestativa. 
En paralelo e integrados en estos núcleos se hallan los conductos verticales de todas las instalaciones, obteniéndose así un racionalismo funcional en las mismas, muy deseable por su unidad, paralelismo y practicabilidad.

Además de estos elementos de unión que totalizan las relaciones en altura, se encuentran las escaleras de público que conectan los tres patios, la escalera privada de caja y las rampas de aparcamiento.

La toma de la rampa de entrada se efectúa a la mitad de la manzana por debajo de la plataforma y sobre la calle Luis Martí. Estas rampas son aptas para el paso cómodo de dos coches. La primera rampa pasa desde la cota de la calle a la del primer sótano, atravesando la entreplanta. La segunda comunica el primer sótano con el segundo, donde termina.

La relación volumétrica entre los diferentes cuerpos se establece a través de profundos retranqueos o estrangulamientos en el volumen del conjunto.

Visualmente, la relación entre las plantas de público y la calle, así como la existente entre

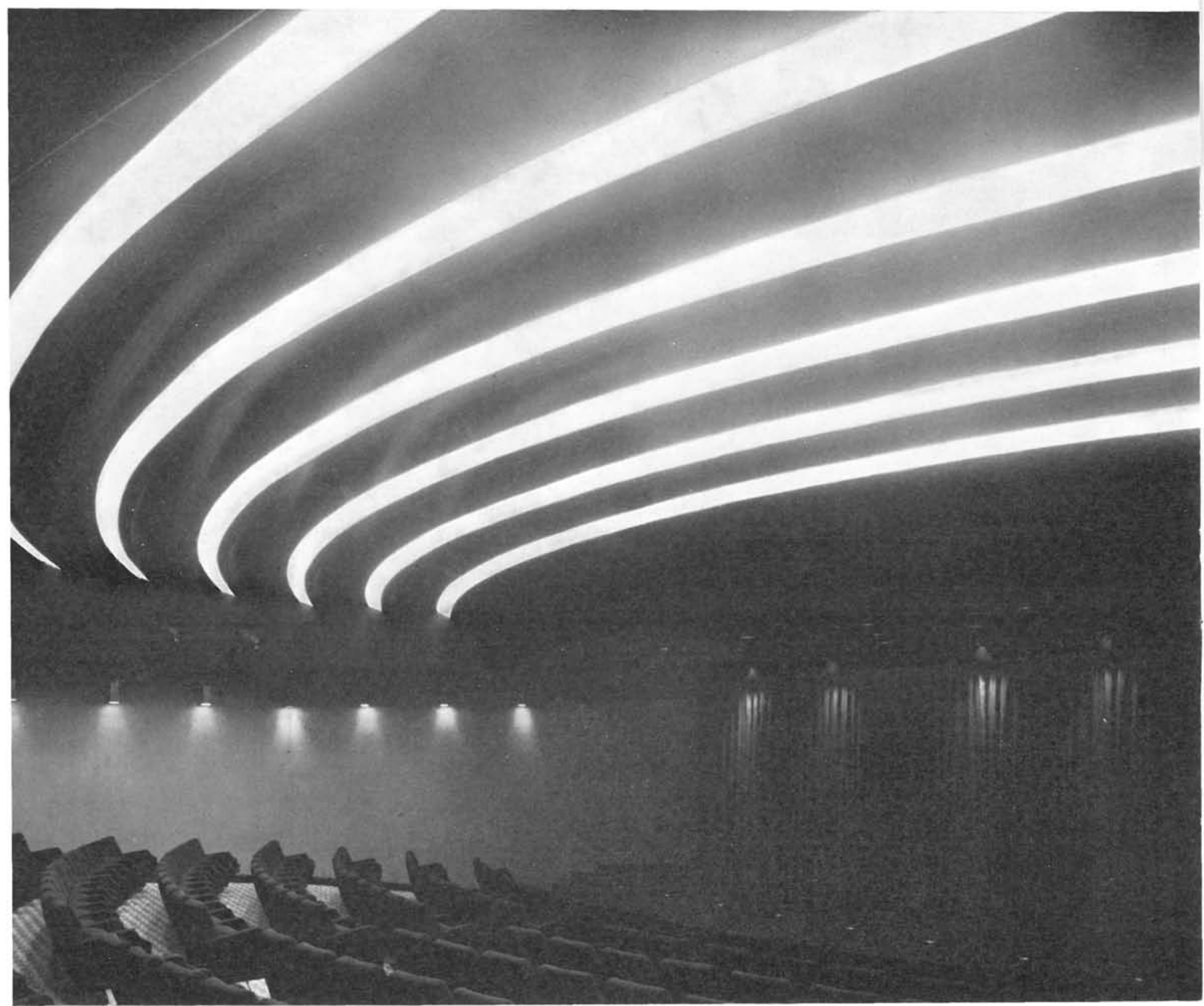




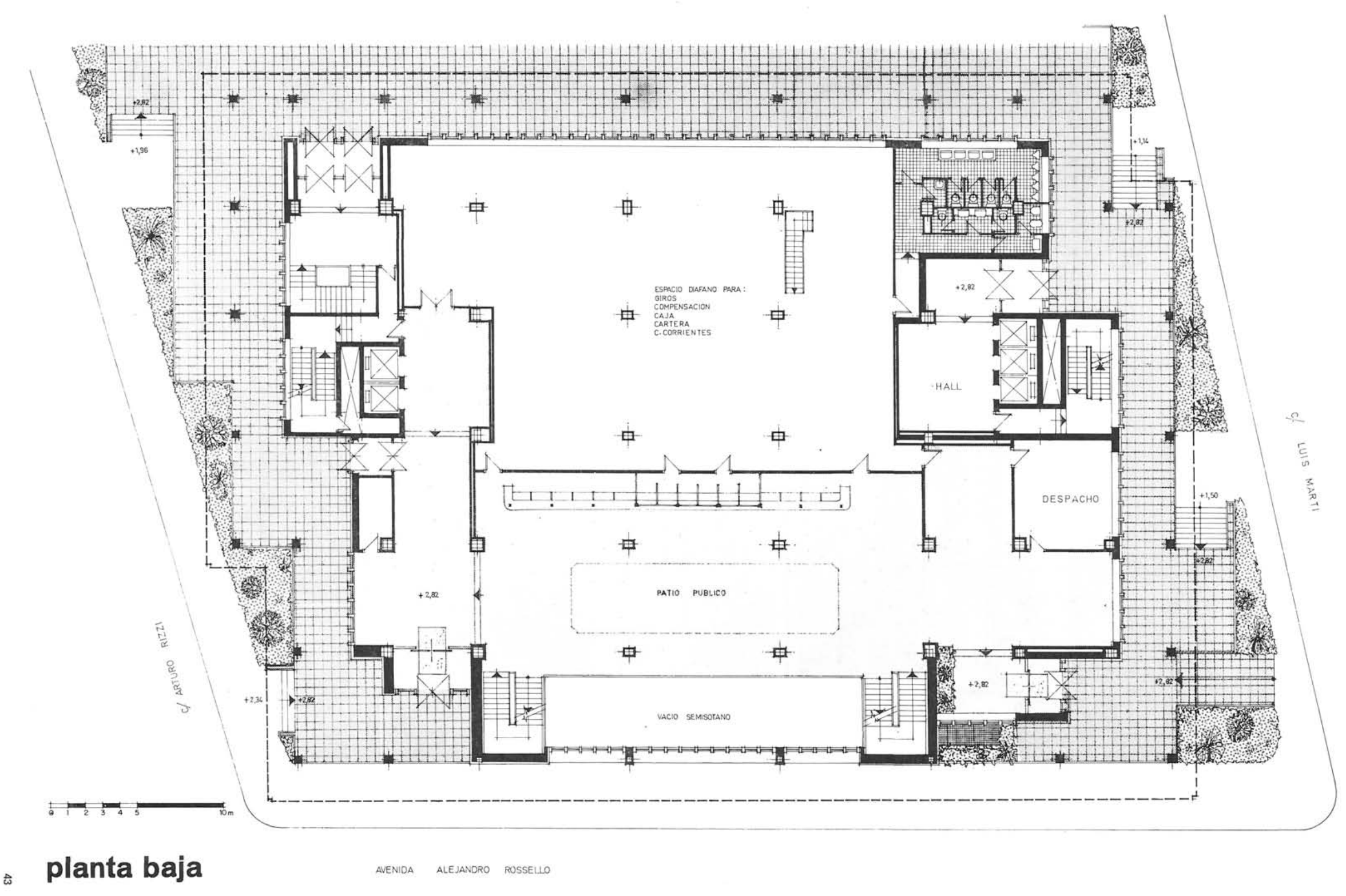


ellas, se realiza mediante interrupciones o vanos rectangulares en los distintos forjados que permiten la conexión espacial y visual de los tres patios de público.

En los sótanos se alojan todas las dependencias de importancia secundaria y necesidades puramente funcionales, tales como: garajes, instalaciones generales y archivos.

En cuanto a la entreplanta hay que resaltar su carácter mixto, por tener servicios de

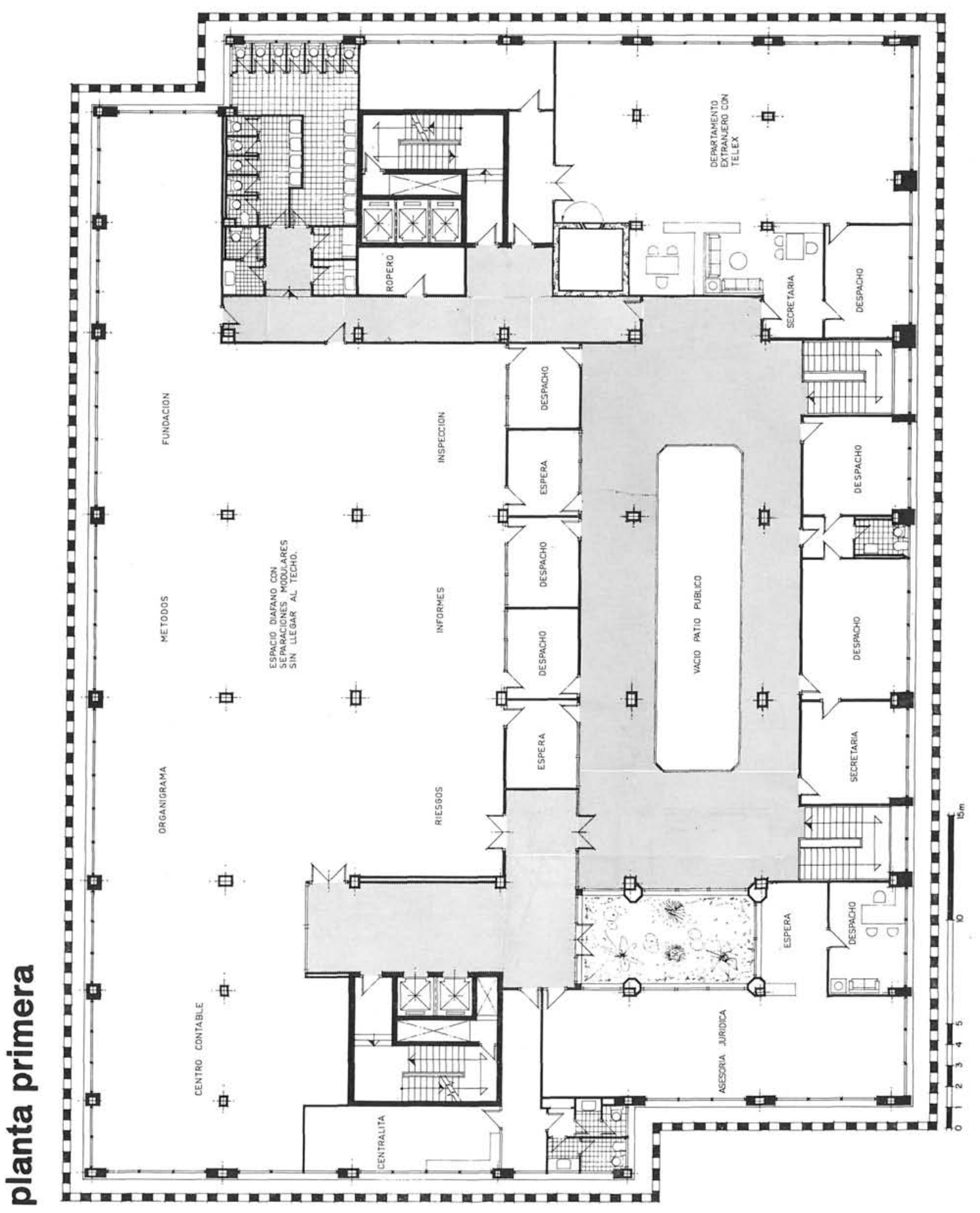


contacto más o menos directo con el público, pero que, por garantía de seguridad y elevadas cargas permanentes y sobrecargas, es oportuno instalar próximas al arranque del edificio.

La planta de acceso está constituida, en su parte fundamental, por el patio de público con dos comunicaciones directas a la calle en sus extremos. El frente oeste, acristalado, vierte la luz directamente sobre este patio de público y también sobre el semisótano, por tener aquél interrumpido el forjado antes de llegar a la fachada. Alrede-

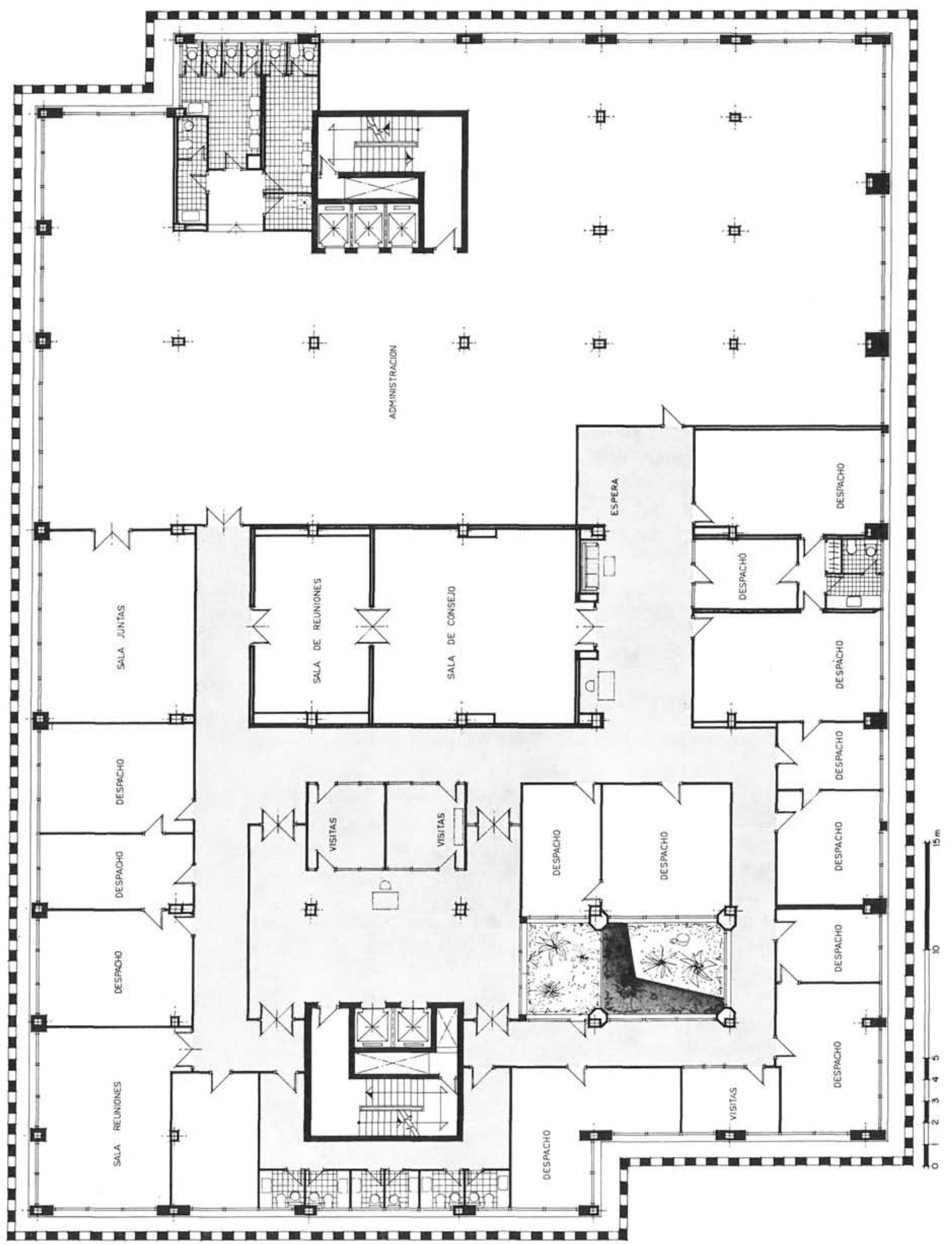

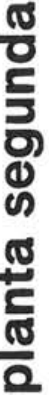




\section{plantas cuarta a séptima}

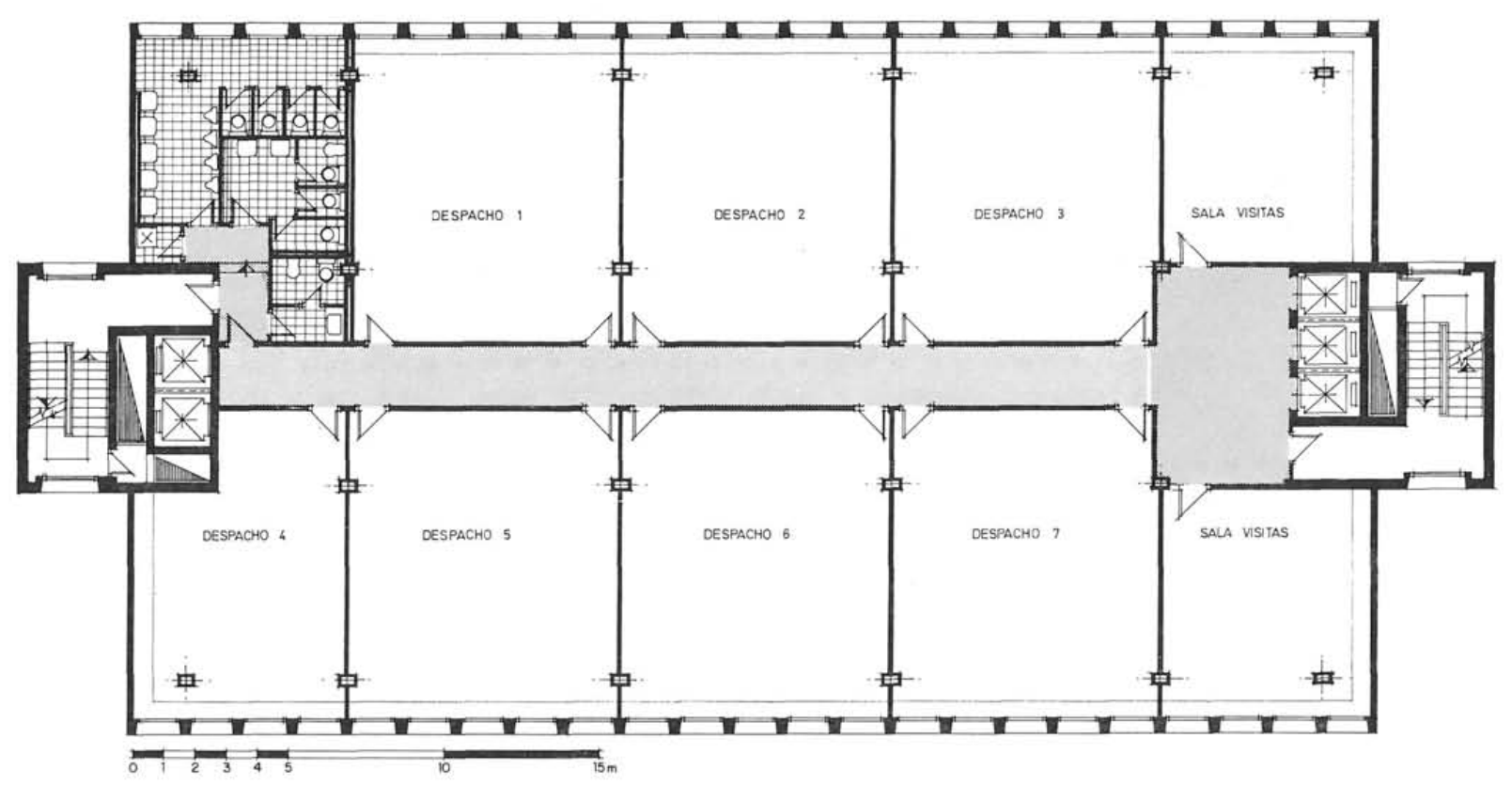

dor y en los otros tres flancos se extienden las oficinas de los departamentos varios, todas ellas con posible comunicación directa sin interferencias en las circulaciones con el público. En esta misma planta y con total independencia del banco figura la entrada al centro cultural.

La planta primera presenta en síntesis la misma formación que la de acceso con las zonas de trabajo no perturbadas por la presencia del público.

En cuanto al ritmo de huecos, esta planta, al igual que la segunda, tiene las cristaleras retranqueadas de la fachada y separadas de ésta por un pasillo periférico, apto para la limpieza de las mismas, constituyendo la fachada propiamente dicha un paramento discontinuo de vanos y macizos no acristalados.

Estas tres plantas constituyen los núcleos nobles del edificio y son, por su situación, los que reciben a la mayor cantidad del público que acude a la Banca.

En las demás plantas se distribuyen las oficinas para el personal directivo y dependencias no afectas al público.

En cuanto al ático aloja dos viviendas para vigilante y conserje, aptas para ellos y sus familias.

En general, las circulaciones de los empleados son absolutamente independientes de las del público, no existiendo ningún tipo de interferencias con las mismas.

El acceso de los empleados es libre, y puede ser, común, paralelo al del público o separado del mismo. El movimiento o circulación dentro de las plantas y entre ellas es estanco y no conflictivo en ningún momento, pudiendo dichos empleados acceder asimismo desde el garaje. Los invitados de la Banca disponen de una entrada lateral y privada, sólo compatible con los empleados, pero segregable de los mismos (a voluntad) mediante ascensores. Pueden tener acceso desde el garaje.

Por lo que se refiere al Centro cultural, admite dos posibilidades de circulaciones:

- Afecta a la Banca con entrada desde los halls de la misma. 


\section{planta \\ primer sótano}

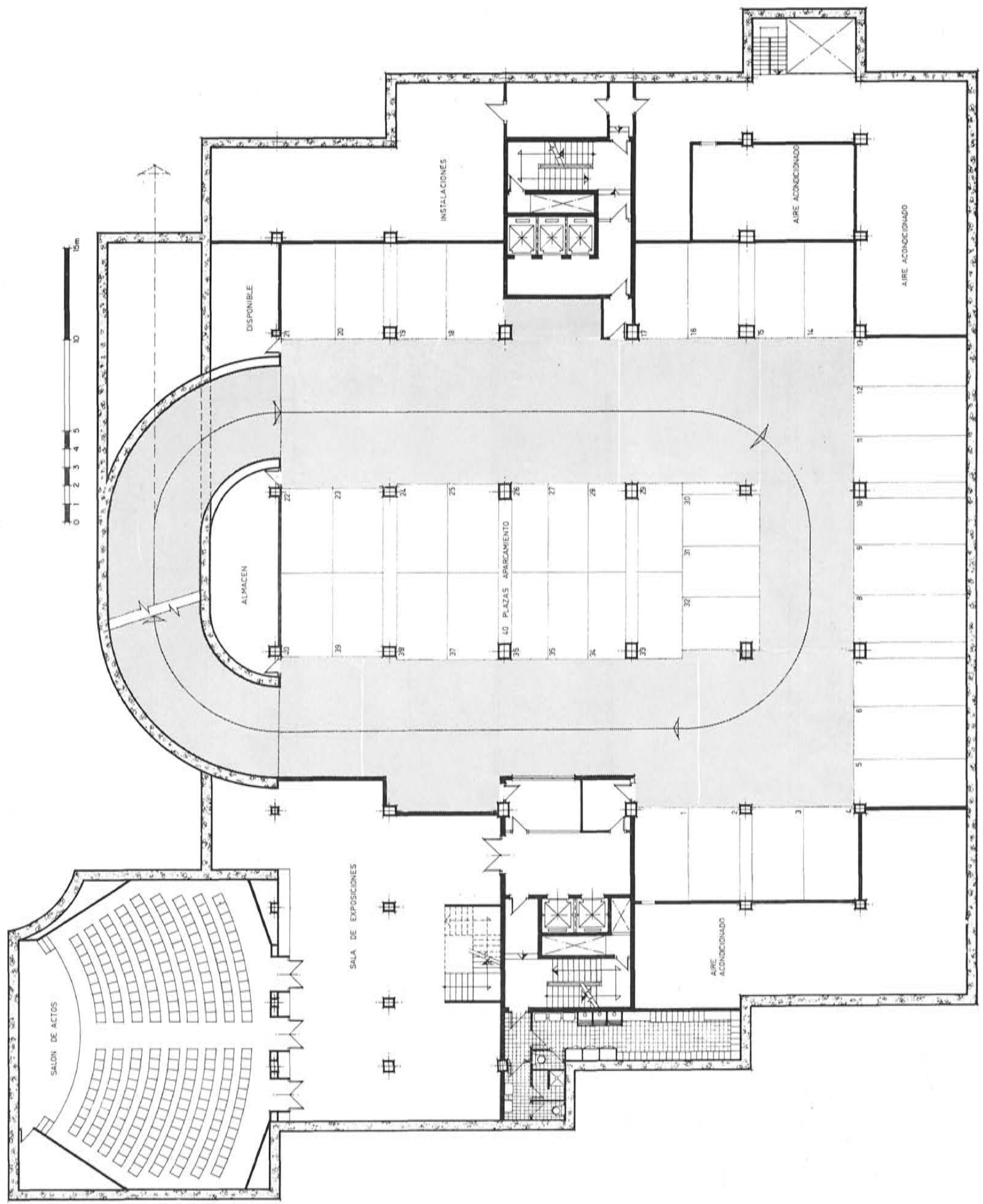




\section{planta}

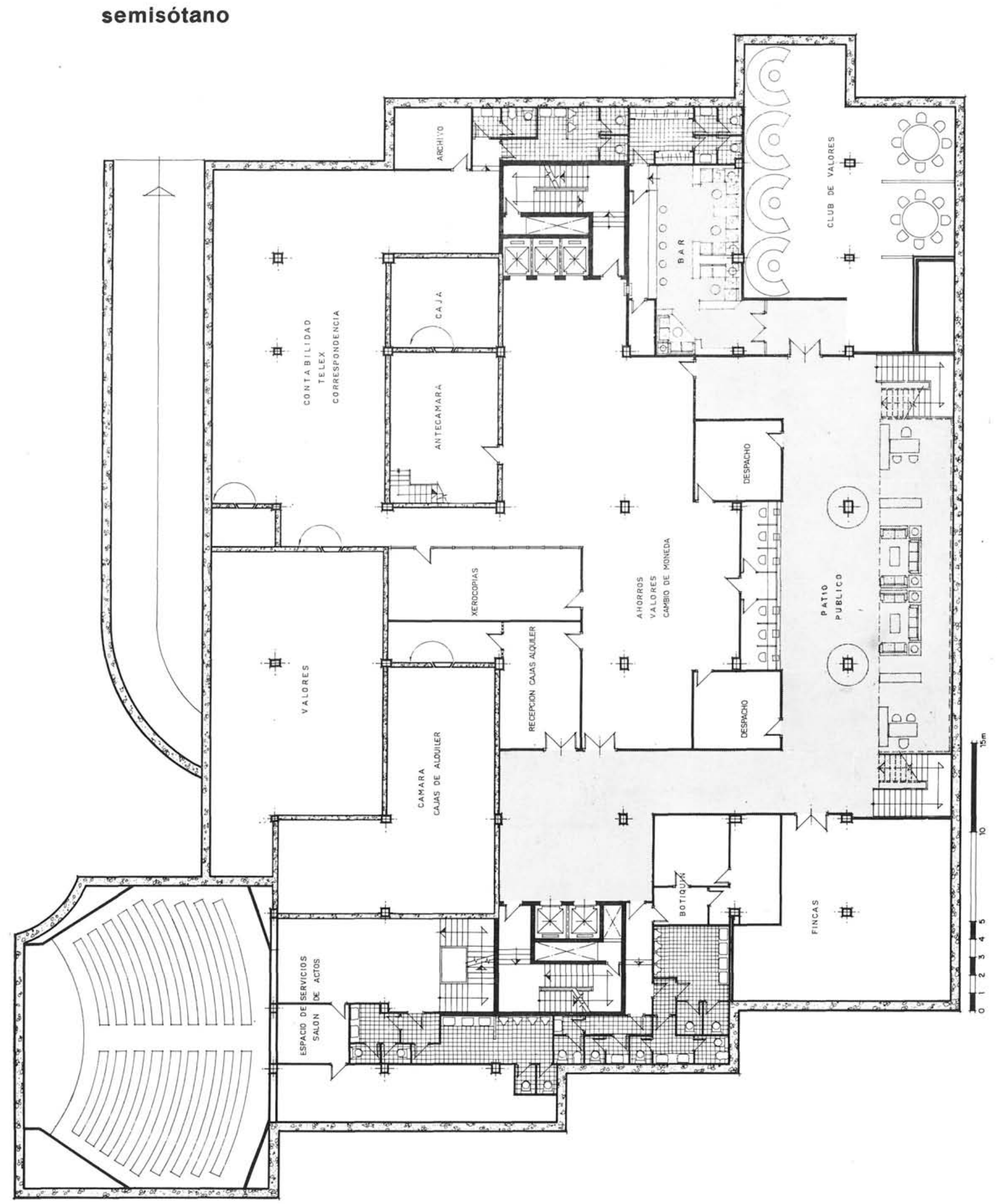


- No afecta a la Banca y funcionando como un centro cultural, independiente de ella, con entrada desde la calle y con todas sus dependencias marginadas del funcionamiento propio de la Banca.

En lucha contra un falso monumentalismo bancario se ha preferido, teniendo en cuenta las posibilidades volumétricas, no perder en ningún momento la escala humana.

Con este fin se han roto los volúmenes, y la planta de acceso recogida y retranqueada ha ganado en intimidad y escala.

En torno al mismo problema de la escala de tan delicada solución en grandes edificios se planeó el cuerpo de bandeja, que si ocupa dos plantas es con el fin de evitar un volado pequeño, de poca entidad, que daría lugar a la sensación de mezquindad tan típica de las marquesinas. Este cuerpo volado avanza sobre el observador y limita notablemente la altura general del edificio, manteniendo el conjunto dentro de una escala, ya no solamente humana sino urbana.

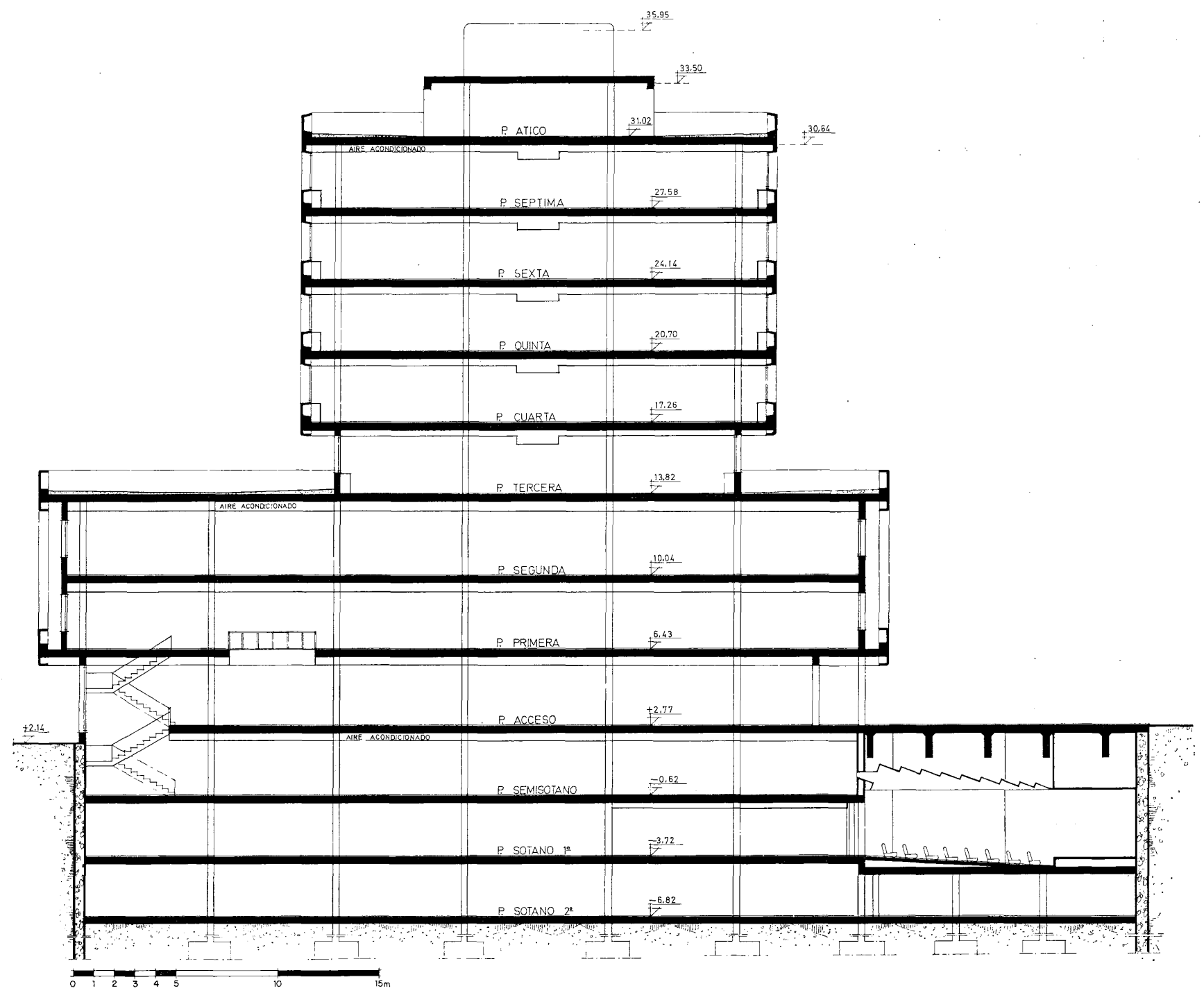




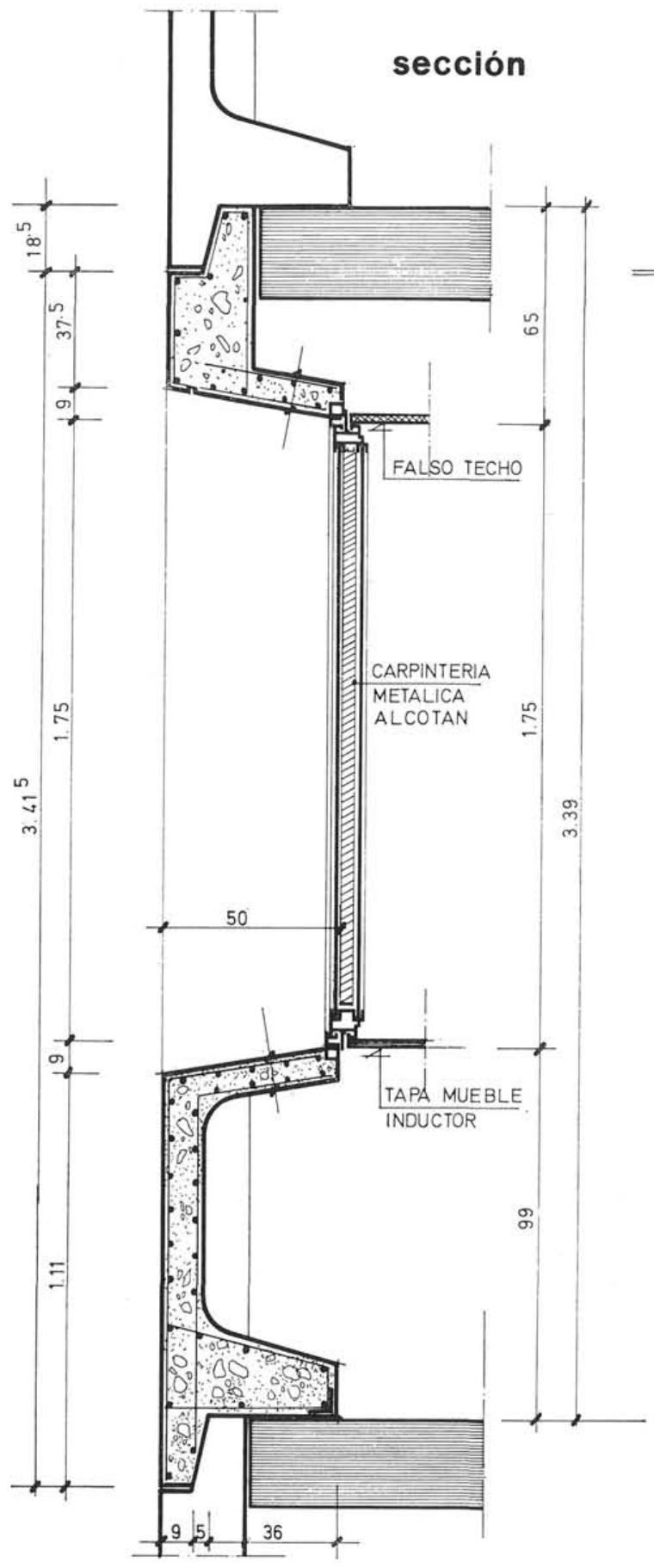

alzado

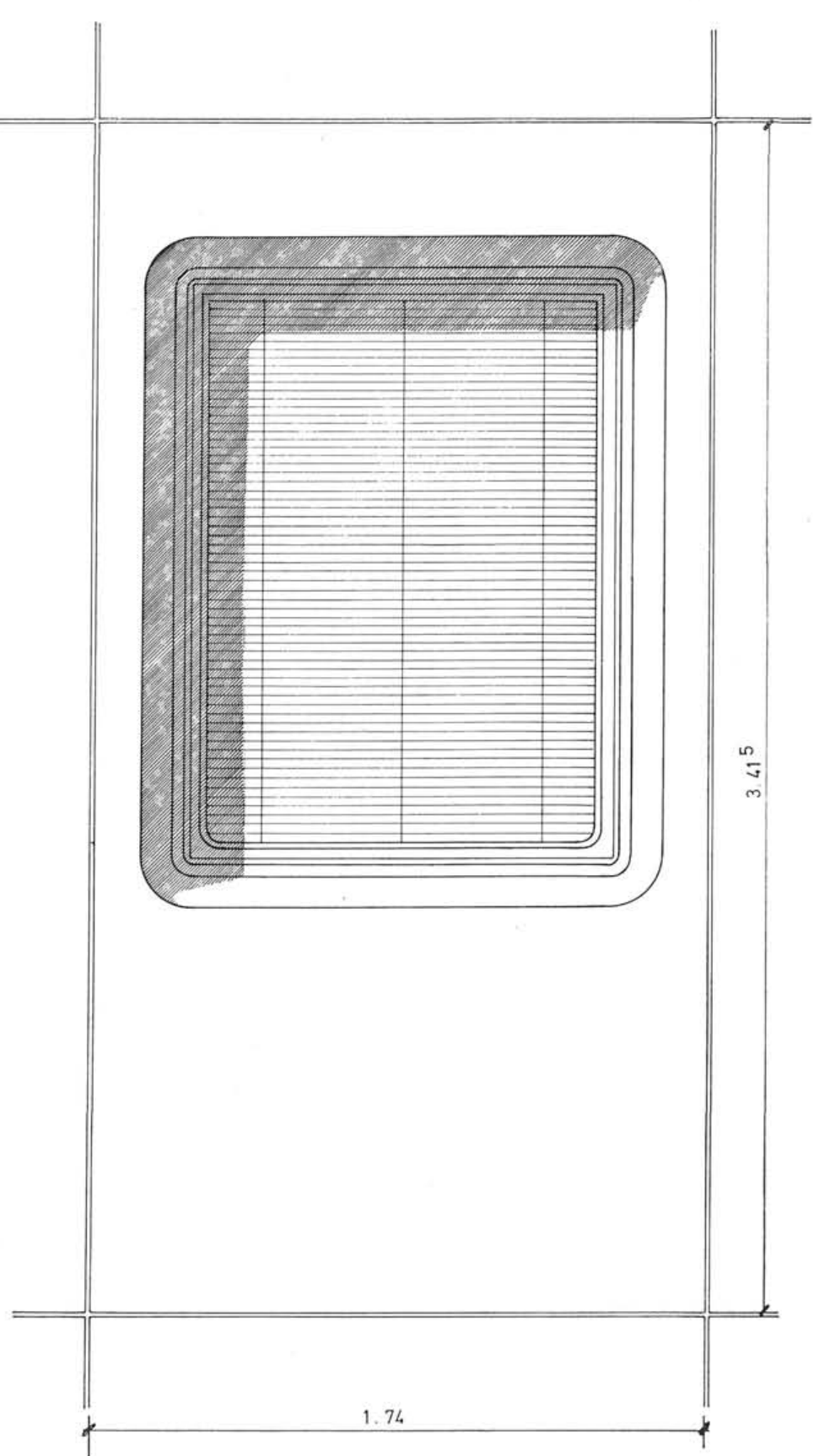

El edificio presenta, tanto en alzados y sección como en planta de cubierta, la formación de maclas de volúmenes

detalle de fachada nítidos paralelepipédicos.

La riqueza de volúmenes queda, por tanto, asegurada sin llegar a grandes excesos. 

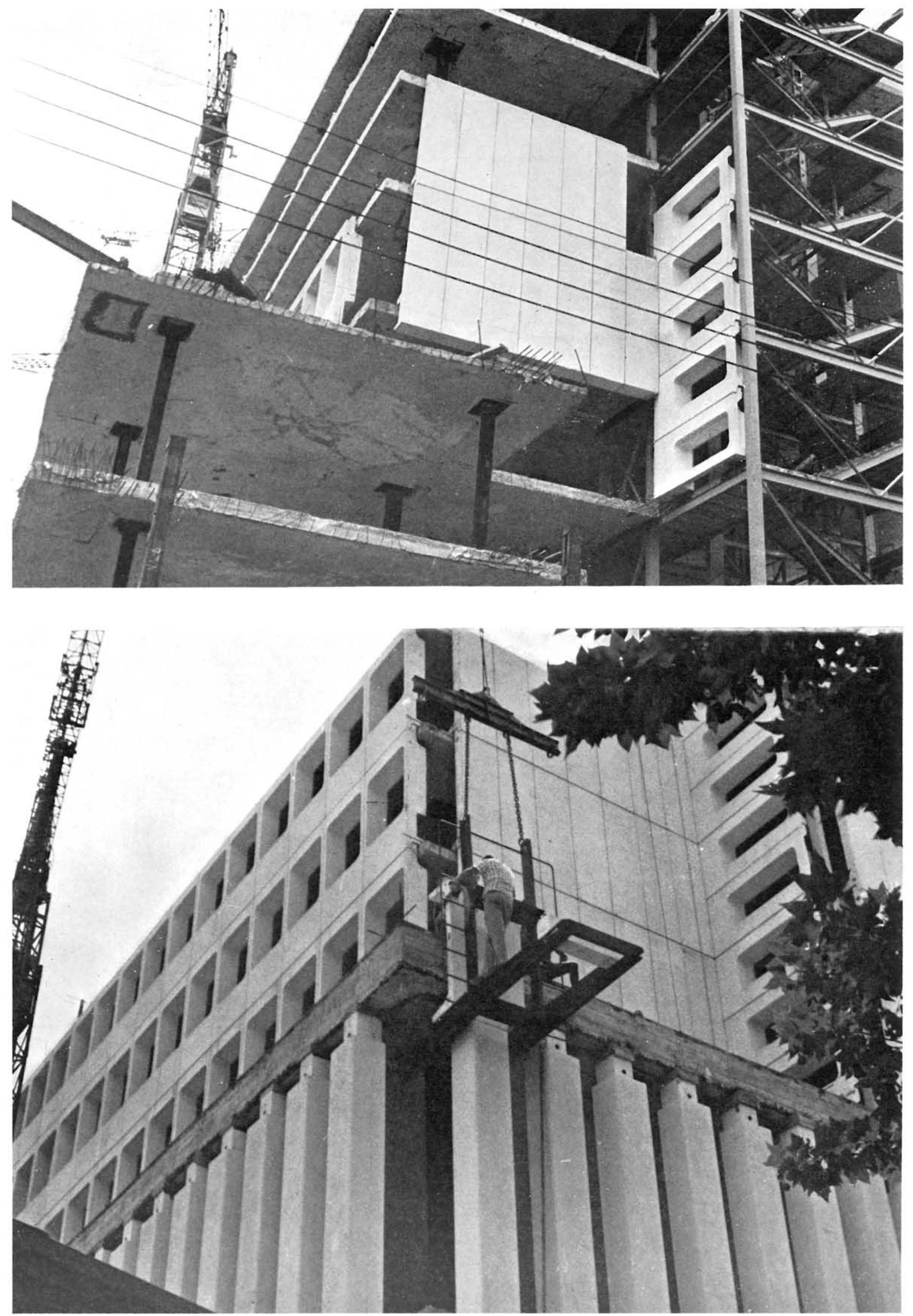


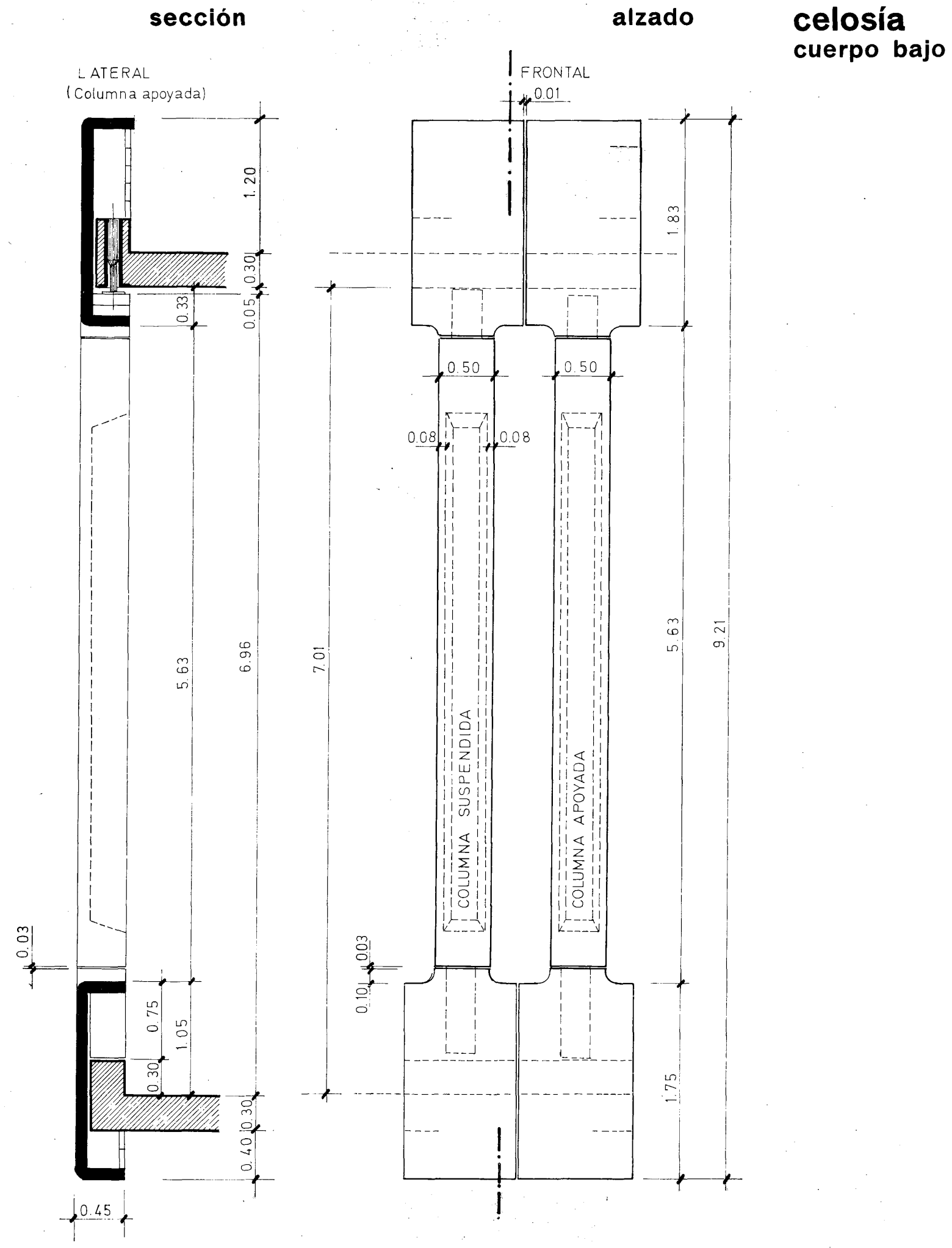

Los volúmenes maclados son absolutamente ortogonales, según el eje vertical y según el eje norte-sur del edificio.

Según eje oeste, y en relación únicamente con estos alzados, todos los encuentros y remates de los volúmenes son acabados con cuartos de bocel o hiperelipses, quedando así "redondeados los cantos", quitándole, pues, violencia a los encuentros y limitando el efecto cortante de los vo- 
lúmenes. Este detalle se acerca al tratamiento habitual de la mayoría de los objetos industrializados que, rara vez, mantienen aristas vivas y rectas en las tres direcciones del espacio.

Las fachadas y paramentos, que han sido realizados con prefabricado escofet, combinan el carácter de limpieza de líneas, corrección racionalista y actualidad del edificio, con las variantes locales -en este caso mediterráneas-, evitando caer en un costumbrismo anecdótico o en tipismo casticista.

La fenestración, que es modulada, proporciona al conjunto su calidad orgánica, a la vez que utiliza un elemento en serie tan de acuerdo con todo el movimiento artístico actual.

Desde el punto de vista funcional, las ventanas van rehundidas en la fachada $75 \mathrm{~cm}$, como corresponde a la adecuación del solea. miento mediterráneo, siendo asimismo un tratamien. to absolutamente arraigado en la cultura e historia arquitectónica local. La fachada de este modo compartimentada y horadada funciona como pantalla acústica, a la vez que retira de la calle el elemento
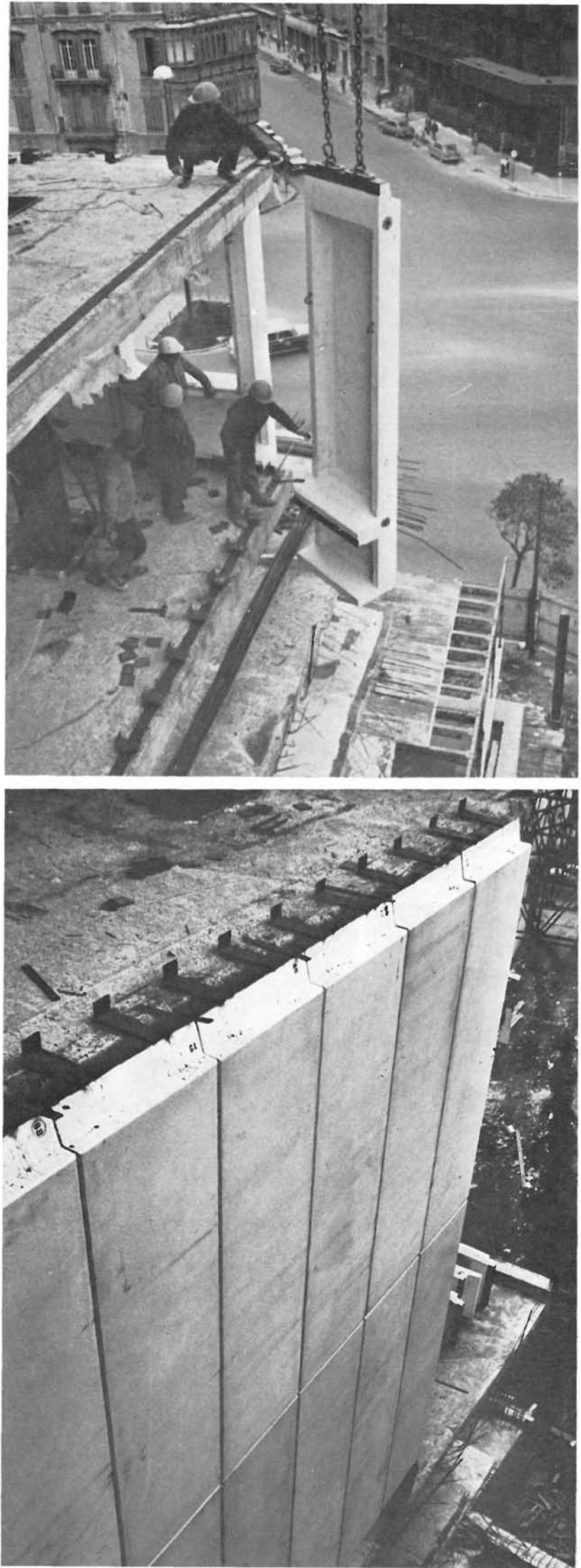


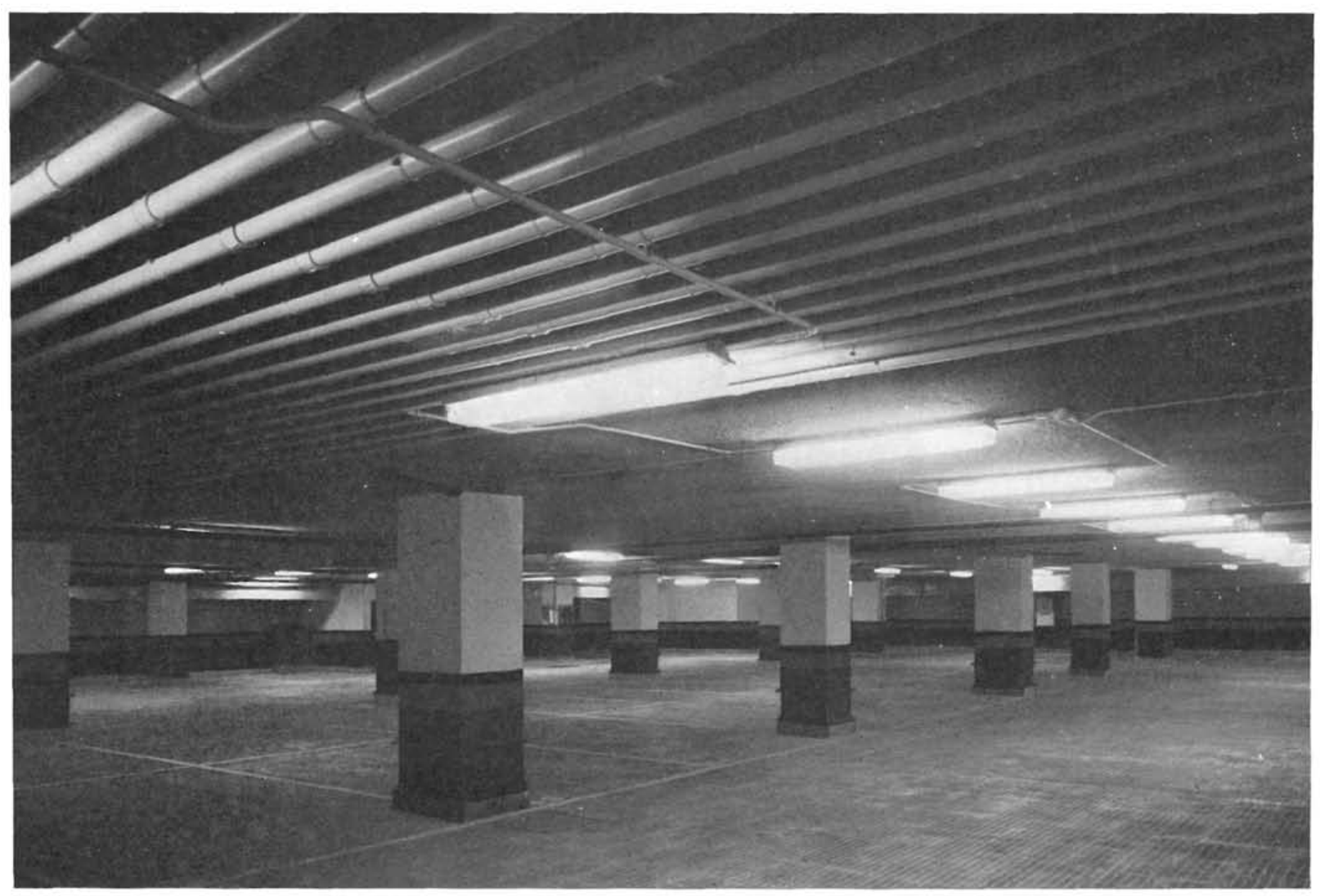

vibrante (vidrio), obteniéndose así un mayor aislamiento acústico natural. La combinación de pantalla acústica y parasol justifica, por sí sola, la utilización de este diseño.

Conviene añadir que el cristal es de excelente calidad aislante y fotofiltrante, así como coloreado en tono oscuro.

Lleva carpintería de aluminio bronceado en ventanas, con los cantos matados, doble luna parasol de color oscuro y persiana graduable en su interior. Están remetidas $75 \mathrm{~cm}$ de la alineación de fachada, como ya se ha dicho antes.

Su fachada es de color blanco, como es normal en los climas mediterráneos, en sus posibles matices (puro, hueso, etc.) por su mínima absorción de los rayos solares y por su espléndida luminosidad tan deseable.

Los acabados interiores tienen las calidades requeridas por el edificio, con techos acústicos de aglomerado o escayola, suelos de moqueta, mármol o cerámica-gres, según los casos, revestimientos verticales de madera y materiales absorbentes de fibra como telas o plásticos. La carpintería interior es canteada y solapada, empleándose en ella maderas finas para barnizar. 


\section{résumé}

Banque March - Palma de Majorque. Espagne

Felipe Lafita, Dr. architecte

Cet immeuble constitue la première phase de tout l'ensemble. II abrite les bureaux bancaires, avec la zone culturelle, les logements des concierges et les appartements pour le personnel de l'organisation. La deuxieme phase -qui sera construite plus les buroaux, les logements et ments.

Le bloc a été aménagé d'une façon ouverie, avec un avantage manifeste pour les usua

L'article fait une description de la solution adoptee, de la distribution et justification de chaque niveau, ainsi que des accès et circulations, des finis des surfaces exté. prumiè March.

\section{summary}

Banca March - Palma de Majorca Spain

Felipe Lafita, Dr. architect

This building constitutes the 1st stage of the overall project and houses the bank offices, with: cultural part, homes for wardens and apartments for organization staff. The 2nd stage - which will be built laterwill include: shop premises, offices, hotel use, homes and apartments.

The block has been arranged in an open style, definitely benefiting users and for the town generally.

The article describes the urbanistic solution adopted, the layout and justification of each floor, as well as accesses and circulation, outdoor and inside finishing of the 1st stage of the building, all intended for the Banca March.

\section{zusammenfassung}

Bank March - Palma de Mallorca. Spanien

Felipe Lafita, Dr. Architekt

Dieses Gebäude bildet die 1. Phase des Gesamtkomplexes und beherbergt die Büroräume der Bank aufgeteilt in: Kulturräume, Pförtnerwohnung und Appartments für das Personal der Organisation. Die 2. Phase, die spater errichtet wird, enthalt: Geschaftsund Appartments.

Zum Vorteil für Benutzer und für die Stadt, wurde der

Der Arteikel beschreibt die angenommene urbanistische Lösung, die Aufteilung und Begründung jedes einzeinen Stockwerkes, die Anfarhtswege sowie äussere und innere fertigstellung des Gebaudes der 1. Phase,

\section{publicación del i.e. t. c.c.}

LAMINAS DE HORMIGON

A. M. Haas

Dr. Ingeniero

Traducción de José M.a Urcelay Dr. Ingeniero de Caminos, Canales y Puertos

El profesor A. M. Haas es personalidad muy conocida en todo el mundo dentro del campo de las estructuras laminares.

El libro, que ha sido traducido a varios idiomas, es de exposición clara e intuitiva, y destaca los conceptos fundamentales sobre los desarrollos matemáticos.

En su primera parte, el libro trata de la teoría de membrana en láminas de revolución. A continuación se aplica esta teoría, para el caso en que las cargas sean también de revolución, a las láminas de revolución más usuales: cúpulas esférica y elíptica, láminas cónicas. depósitos.

Se estudian seguidamente las láminas de revolución sometidas a cargas que no sean de revolución, así como las tensiones secundarias debidas a flexiones en láminas de revolución.

Se termina la primera parte con un capítulo dedicado a la construcción de láminas.

En la segunda parte se estudia la teoría de membrana para láminas rebajadas, dedicando sendos capítulos a las láminas en paraboloide hiperbólico, en paraboloide elíptico y en conoide.

A continuación se dedica un extenso capítulo a la flexión.

Seguidamente se estudia el caso de pequeñas cargas que originan fuertes tensiones por flexión.

Finalmente, el libro dedica un capítulo al pandeo.

Un volumen encuadernado en tela, brillantemente presentado, de $17 \times 24,5 \mathrm{~cm}$, compuesto de 420 páginas, numerosas figuras, tablas y ábacos. Precios: España, 1.250 ptas.; extranjero, \$25. 